ISSN 1991- 8690

website : http:// jsci.utq.edu.iq

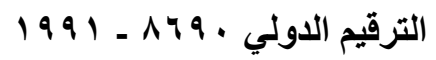

Email: utjsci@utq.edu.iq

\title{
Preparation and study Impact and Hardness Strength for Gravel Nano Particles /Polyester Composites
}

\author{
Abbas Fadhil Essa \\ Ahmed Jadah \\ Najlaa Jerjack
}

Department of Physics- College of Science- University of Wasit.

\begin{abstract}
$\underline{\text { Abstract }}$
In view of the developments of industrial applications, this happened in recent years and the need to use composite materials in general and polymer composite especially in the various industrial applications developed. This work focuses on studying the addition effect of the prepared gravel nanoparticles (different types) with particles size of $(121.74 \mathrm{~nm})$ for type( I ) and (100.16 nm)for type( II ) as a nano particles with different weight percentages (10, 20, 30, 40) $\%$ to the unsaturated polyester resin (UPE) as a matrix to prepare polyester nanocomposites . The molding method was used to prepare polyester and their nanocomposites sheets. The mechanical properties were studied including Impact strength and Hardness strength for the samples. The results showed that the samples of Gravel nanocomposite type ( I ) gained highest values of Impact strength $\left(4.508 \mathrm{KJ} / \mathrm{m}^{2}\right)$ at ratio percents $(40 \%)$ and the samples of Gravel nanocomposite type (II ) gained highest values of Impact strength $\left(5.509 \mathrm{KJ} / \mathrm{m}^{2}\right)$ at ratio percents $(40 \%)$. Also the results show that the UPE / Gravel nanocomposite type (II ) gained highest values of Impact strength $\left(5.509 \mathrm{KJ} / \mathrm{m}^{2}\right)$ at ratio percents (40\%) compared with UPE / Gravel nanocomposite type ( I ) $\left(4.508 \mathrm{KJ} / \mathrm{m}^{2}\right.$ ). Also the results showed that the samples of Gravel nanocomposite type (I) gained highest values of shore D number (91.65 H.NO.) at weight percentage (40\%) of Gravel nano particales. While the samples of Gravel nanocomposite type (II) gained highest values of shore D number (90.00 H.NO.) at weight Percentages (10\%, 20\%).
\end{abstract}

Keywords: - Gravel nanoparticles , Unsaturated Polyester Resin, and nanoComposite Materials.

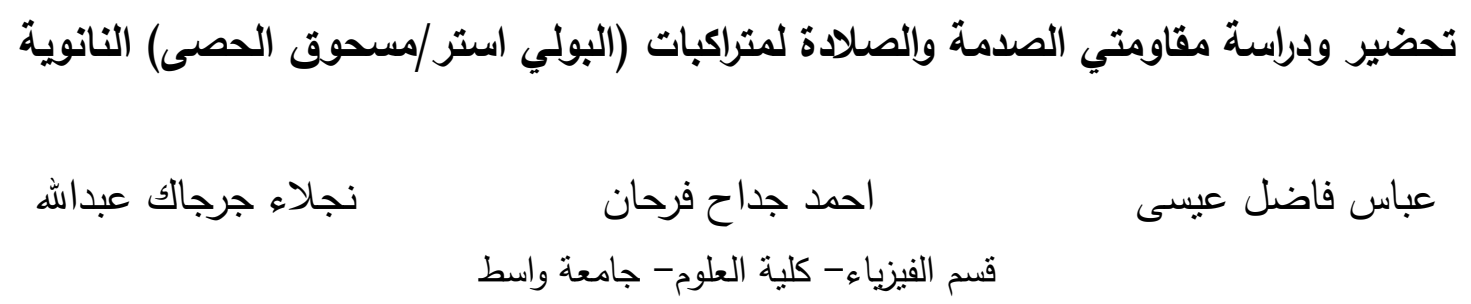

الخلاصة

نظرا للنطورات في النطبيقات الصناعية التي حصلت في السنوات الأخيرة والحاجة الى استخدام المواد المتراكبة بشكل عام والمتراكبة الوليمرية بشكل خاص في مختلف النطبيقات الصناعية المتقدمة. في هذه الدراسة تحضير عينات من متراكبات نانوية من راتتج البولي استر مضاف اليه نوعين مختلفين من

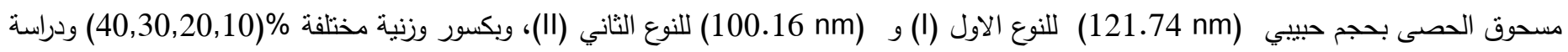
تاثير اضافة مسحوق الحصى الناعم على الخواص الميكانيكية للبولي استر . استخدمت طربقة القولبة اليدوية في تحضير عينات المواد المتراكبة النانوية، وتم

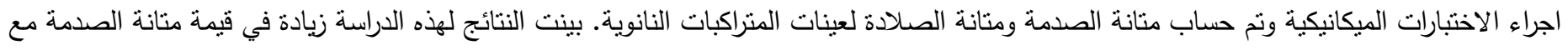

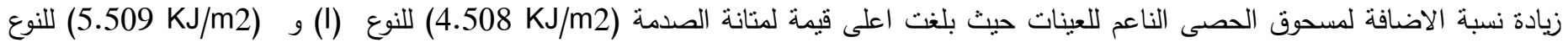

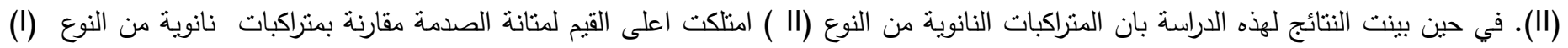




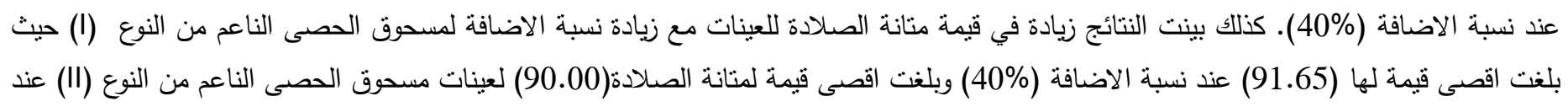
نسب الاضافة (10\% (10\%)

\section{Introduction}

Composite materials can include fillers of various sizes. In engineering such micro-composite materials are of the greatest importance, the maximum cross size of which usually does not exceed $10 \mu \mathrm{m}$. Concentration is generally considered to be one of substantial parameters influencing the whole composite properties. [1] Polymer matrix composite materials are considered as modern materials in most of engineering and technical applications.Particulate reinforced composites constitute a large portion of these new advanced materials.Thermosetting resins modified with inorganic particles such as carbon, Tio2, Sio2, Al2O3, clay. For inorganic / organic composites, the size of particles and the interfacial adhesion have great effect on the properties of the resin matrix. [2, 3] Aggregate is the component of a composite material that resists compressive stress and provides bulk to the composite material. For efficient filling, aggregate should be much smaller than the finished item, but have a wide variety of sizes. For example, the particles of stone used to make concrete typically include both sand and gravel. [4]Composites typically use thermoset resins which, begin as liquid polymers and are converted to solids during the molding process. This process, known as cross linking, so that the composite materials have chemical resistance, higher mechanical properties and greater structural durability than thermoplastics. [5]Young and Beaumont [6], group of researchers [7], Sewench and Najlaa [8], Hanaa [9] and Wasan [10] studied silica powder, wood flour and rice husk,coconut shell particulates, zinc oxide\& Aluminum oxide and particles of glass based composite respectively.

\section{The aim of this work is to}

Fabrication of UPE / Gravel nano composites. Evaluation of mechanical properties of the nano composites.Prepare material nano composite important in industrial applications such as waste water pipes.

\section{Materials and Methods}

\section{(A) Raw Materials}

The materials used to prepare the nano composites are unsaturated polyester (UPE) resin type (A-50) with the hardener MEKP and with accelerator cobalt naphthenate (having a symbol SIR SIROPOL) which was supplied from Saudi industrial resin CO. LTD, p.o.box 7764, Jeddah 21472, kingdom of Saudi Arabia,and two different types of fine gravel powder were used in this research as follow:

1- Gravel nanoparticles type I (take from badra quarry/ Wasit-Iraq) with particles size of (121.74 $\mathrm{nm}$ ) was used in this work as a filler materials shown in Fig. (1-a).

2- Gravel nanoparticles - type II (take from Ali Alghrbi quarry / Misan-Iraq) with particles size of $(100.16 \mathrm{~nm})$ was used in this work as a filler materials shown in Fig. (1-b).

The compositions of these materials are stated in the table (1).

Table (1): Chemical composition for Fine Gravel Powder (I and type II)

\begin{tabular}{|c|c|c|c|c|c|c|c|c|c|c|}
\hline \multirow{2}{*}{$\begin{array}{l}\text { Type of } \\
\text { Gravel }\end{array}$} & \multicolumn{10}{|c|}{ Components } \\
\hline & $\mathrm{SiO}_{2}$ & $\mathrm{Al}_{2} \mathrm{O}_{3}$ & $\mathrm{Fe}_{2} \mathrm{O}_{3}$ & $\mathrm{CaO}$ & $\mathrm{MgO}$ & $\mathrm{Na}_{2} \mathrm{O}$ & $\mathrm{K}_{2} \mathrm{O}$ & $\mathrm{MnO}$ & $\mathrm{Pb}_{2} \mathrm{O}_{3}$ & $\mathrm{Cu}_{2} \mathrm{O}$ \\
\hline Type I & $29.0 \%$ & $0.32 \%$ & $6.96 \%$ & $23.24 \%$ & $1.91 \%$ & $0.44 \%$ & $0.49 \%$ & $0.11 \%$ & $0.018 \%$ & $0.004 \%$ \\
\hline Type II & $0.96 \%$ & $0.14 \%$ & $2.16 \%$ & $53.67 \%$ & $0.84 \%$ & $0.006 \%$ & $0.006 \%$ & $0.019 \%$ & $0.013 \%$ & ….. \\
\hline
\end{tabular}

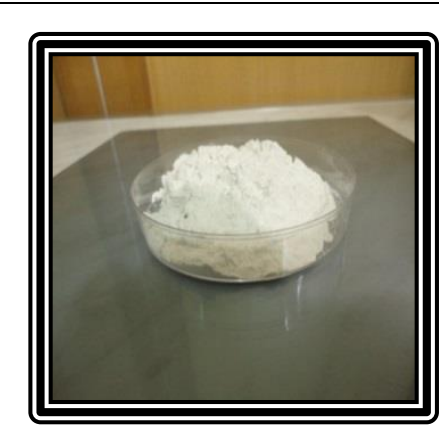

(a)

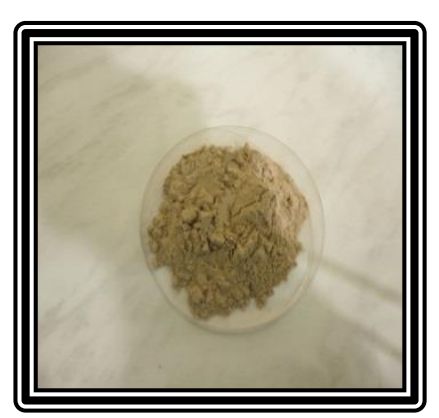

(b)
Fig. (1) (a) Photograph shows Gravel nanoparticales type I (b) Photograph shows Gravel nanoparticales type II

\section{(B) Cast Mould}

The cast mould used for casting the polymeric specimens and composites 
1. A glass plates of dimensions $(400 \mathrm{~mm} \times 400$ $\mathrm{mm} \times 6 \mathrm{~mm}$ ) were used as a mould stages.

2. Glass strips of dimensions $(200 \mathrm{~mm} \times 20 \mathrm{~mm} \times$ $6 \mathrm{~mm}$ ) were used as boundaries for the cast mould.

Before casting, a glass plates were cleaned with water and soap solution, after drying in oven, one base of the glass plates was coated with wax, then glass strips were fixed on glass plates and left for one hours to dry at room temperature.

\section{(C) Composites Preparation}

The nano composites were prepared from unsaturated polyester resin (as a matrix) and the two different types of Gravel nano particles (as a particles fillers) with different weight percentages of $(10,20,30$ and 40$) \%$ by molding method which can be summarized by the following steps:

1. Determine the weight Gravel nanoparticles by using a sensitive balance (four digits).

2. Determine the weight of resin and its hardener and mix them carefully.

3. Mix the content thoroughly in a clean disposable container by a fan type stirrer before casting it as sheets (of dimensions $200 \mathrm{~mm} \times$ $150 \mathrm{~mm} \times 6 \mathrm{~mm}$ ) by using glass mould.

4. Leave the nanocomposite at room temperature about 24 hours and then for post-curing, the sheets were left for 2 hours in an oven at temperature $60^{\circ} \mathrm{C}$.

\section{(D) Impact Test sample cutting}

The sheets of the nanocomposites are cutting into specimens, by using a circular iron saw, pluses from the samples were removed by using the iron rasp, the samples were polished by using abrasive emery papers of grade 400.The shape and dimension of the samples cut for impact test according to [ASTM-D790-84] shown at Figure (2) and Figure (3).

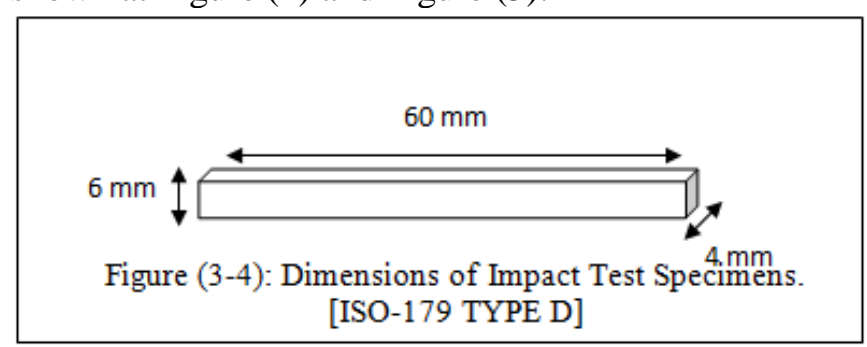

Figure (2): Dimensions of Impact Test Specimens. [11] [ISO-179 TYPE D]

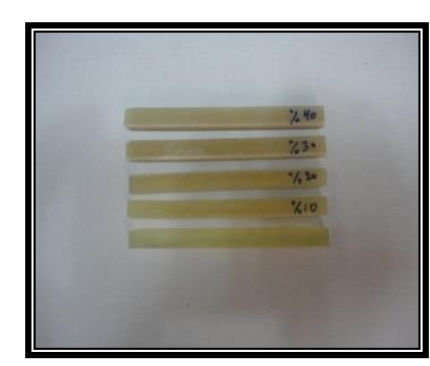

(a) (b)

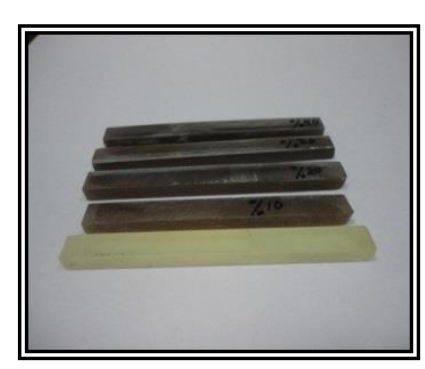

Figure (3): Photograph of Impact Test Specimens before testing.

(a) pure polyester and Gravel /polyester nanocomposites type (I) samples.

(b) pure polyester and Gravel /polyester nanocomposites type (II) samples.

\section{Charpy Impact Test}

Pendulum-type hammers testing machine model IMPACT TESTER TMI NO 43-1 was used in the charpy impact mode of full scale $2 \mathrm{~J}$. In Charpy type the specimen is supported as a horizontal simple beam and is broken by a single swing of the pendulum with the impact line midway between the supports. In this method used a special un notched specimen according ISO-179 standard (Type-D).

Impact strength is calculated from the relation. [12]

I.S =U/A $\quad\left(\mathrm{KJ} / \mathrm{m}^{2}\right)$

Where

I.S = impact strength

$\mathrm{U}=$ Energy of fracture in (kilo joule)

$\mathrm{A}=$ Cross section area in $\left(\mathrm{m}^{2}\right)$

\section{Hardness Test}

Shore D Durometer Hardness instrument fabricated by TIME GROUP INC Company, and was used to carry out the hardness test by using pointed dibbing tool. The pointed dibbing tool penetrate the material surface by the pressure applied on the instrument where the dibbing tool head touching quite the surface of the samples then calculate the hardness values for the samples.

\section{Results and Discussion}

\section{A) Impact Strength of Composites}

From the obtained results the behavior of curves show different characteristics according to the filling material and its properties (weight percentage, particles 
size, shape, density, etc.). The conventional charpy impact test is used to evaluate the impact strength of the nanocomposite that have $(10,20,30,40) \%$ of gravel nanoparticles. The results of this test are shown in Tables (2), Fig. (4) and Fig. (5), which show the effect of gravel content on the impact strength values of the prepared nanocomposite. Now selecting the optimum ratio among four ratios; (90\%-10\%, 80\%-20\%, 70\%$30 \%$, \& 60\%-40\%), which gave the best impact strength, the ratio is $(60 \%-40 \%)$ of UPE and Gravel nanoparticles for two types of gravel. The Tables (2) showed that the samples of Gravel nanocomposite type ( I ) gained highest values of Impact strength (4.508 $\mathrm{KJ} / \mathrm{m}^{2}$ ) at ratio percents $(40 \%)$ and the samples of Gravel nanocomposite type (II ) gained highest values of Impact strength $\left(5.509 \mathrm{KJ} / \mathrm{m}^{2}\right)$ at ratio percents $(40 \%)$. The addition of Gravel nanoparticles in ratio of $40 \%$ to UPE is the right addition to gain free movement for the chains to absorb as much energy as possible which means that interference between UPE and FGP at the ratio $(60 \%-40 \%)$ leads to improvement of the compatibility between the two materials UPE and FGP. Table (2) demonstrate that the Charpy impact strength of (thermoset /reinforcement material) composites is higher than that of brittle matrix itself, which implies the positive role of reinforcement material on the impact fracture toughness of brittle materials. The good adhesion between the UPE resin and Gravel nanoparticles is behind the improved values of impact strength for UPE nanocomposites, whereas, the higher value of the impact strength of the composites material consisting of the reinforced with gravels particles can be attributed to the strong interfacial adhesion between UPE and Gravel nanoparticles. Also, it is ascribed to the stringing of the chemical bond and interaction between the matrix and fillers materials. Also the results show that the UPE / Gravel nanoparticles type (II ) gained highest values of Impact strength (5.509 $\mathrm{KJ} / \mathrm{m}^{2}$ ) at ratio percents (40\%) compared with UPE / Gravel nanoparticles type ( I ) $\left(4.508 \mathrm{KJ} / \mathrm{m}^{2}\right)$ as shown in Fig. (6) and Fig. (7),

Table (2): The effect of gravel content (wt. \%) on the (I.S) of (UPE/ nanoGgravel) nanocomposites.

\begin{tabular}{|c|l|l|l|l|}
\hline \multirow{2}{*}{ Composition } & \multicolumn{4}{|l|}{ Impact Strength (I.S), KJ/m ${ }^{2}$} \\
\cline { 2 - 5 } & \multicolumn{3}{|l|}{ Gravel nanoparticles content (wt. \%) } \\
\cline { 2 - 5 } & $10 \%$ & $20 \%$ & $30 \%$ & $40 \%$ \\
\hline UPE/nano Ggravel type I & 3.115 & 3.240 & 3.355 & 4.508 \\
\hline UPE/nano Ggravel typeII & 2.983 & 3.233 & 3.450 & 5.509 \\
\hline
\end{tabular}

I. $\mathrm{S}_{\mathrm{UPE}}=2.7 \mathrm{KJ} / \mathrm{m}^{2}$

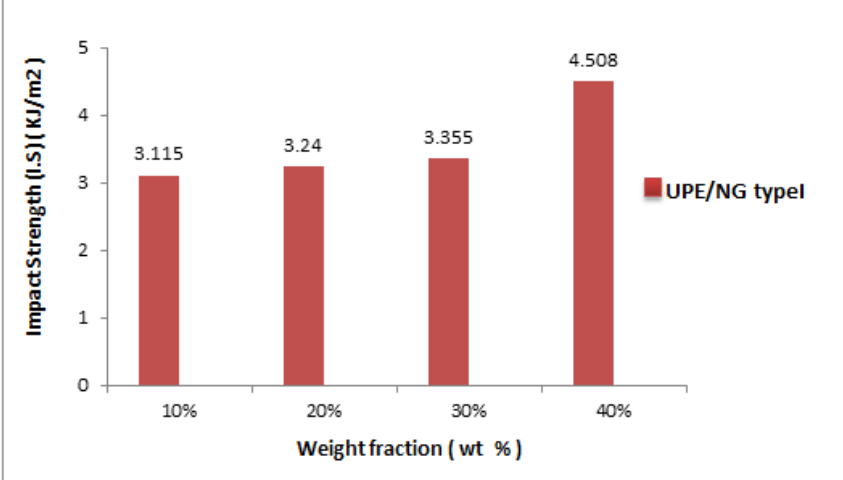

Fig. (4): Charpy impact strength variation with Nano Gravel (NG) (type I) content in UPE resin

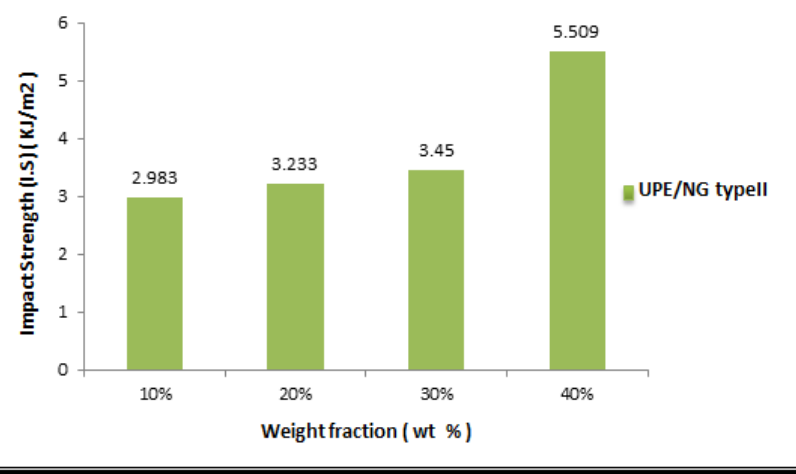

Fig. (5): Charpy impact strength variation with Nano Gravel (NG)(type II) content in UPE resin

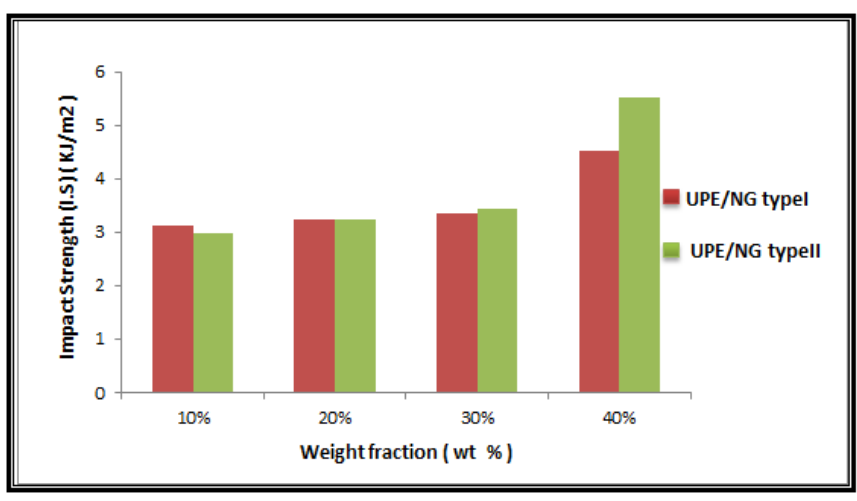

Fig. (6): Charpy impact strength variation with NanoGravel (NG)(types I and II) content in UPE resin. 


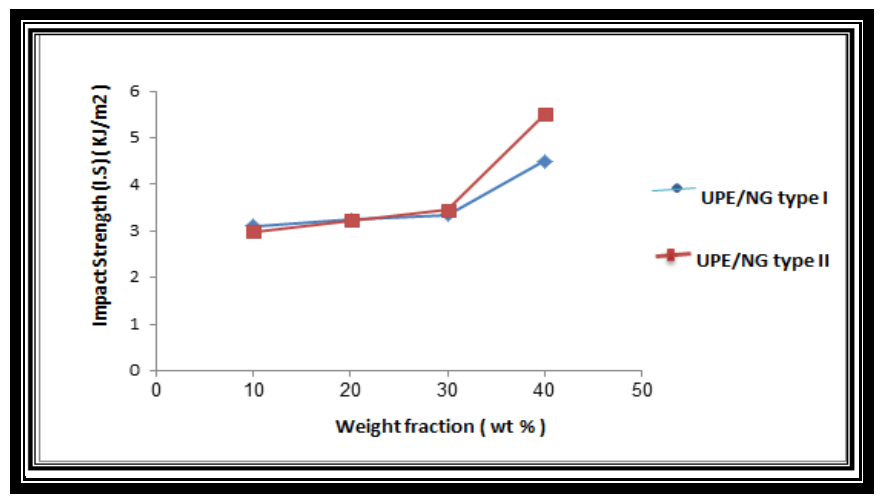

Fig. (7): Charpy impact strength variation with NanoGravel (NG) content in UPE resin

\section{Hardness test}

The shore $\mathrm{D}$ hardness values indicate that the best results were achieved for the particle composite material consisting of unsaturated polyester resin reinforced with different types of gravels nanoparticles compared with UPE pure. The explanation of that as follows: The results showed an increase in the value of shore D number for all the samples of UPE /Gravel nanocomposite type ( I ) at ratio percents (40\%), where the samples of UPE /Gravel nanocomposite type ( I ) gained (91.65H.NO.) as showed in the Table (3) and Figures (8) to (11). Also it showed a slight decrease in the value of shore D number for all the samples of UPE / Gravel nanocomposite type ( II ) at ratio percents $(40 \%)$. where the samples of UPE / Gravel nanocomposite type ( II ) gained (83.35 H.NO.). While the samples of Gravel nanocomposite type (II ) gained highest values of shore D number (90.00 H.NO.) at weight percentages $(10 \%, 20 \%)$. This situation can be explained as the existence of strong bonding at the matrix - particle interface, which leads to high shore D hardness number for sample of nanocomposites reinforced with gravel powder. The matrix transfers some of the applied stress to the particles, which bear a fraction of the load. [13]

Table (3): Shore D hardness of UPE / nanoGravel nanocomposites content in UPE resin.

\begin{tabular}{|l|l|l|l|l|}
\hline \multirow{3}{*}{ Composition } & \multicolumn{4}{|l|}{ Hardness No. } \\
\cline { 2 - 5 } & \multicolumn{3}{|l|}{ Gravel nanoparticles content (wt. \%) } \\
\cline { 2 - 5 } & $10 \%$ & $20 \%$ & $30 \%$ & $40 \%$ \\
\hline UPE/nanoGgravel type I & 86.10 & 88.05 & 91.00 & 91.65 \\
\hline UPE/nanoGgravel typeII & 90.00 & 90.00 & 88.15 & 83.35 \\
\hline
\end{tabular}

Hardness No.uPE $=80$

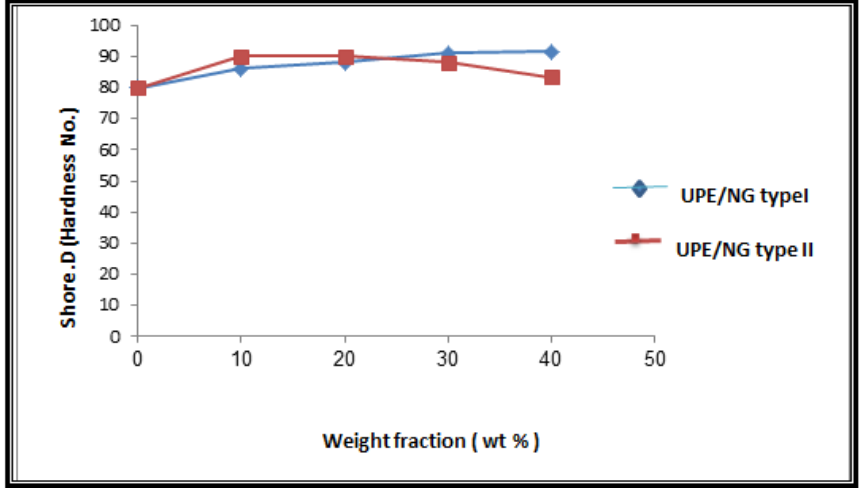

Fig. (8): Charpy impact strength variation with NanoGravegl content in UPE resin

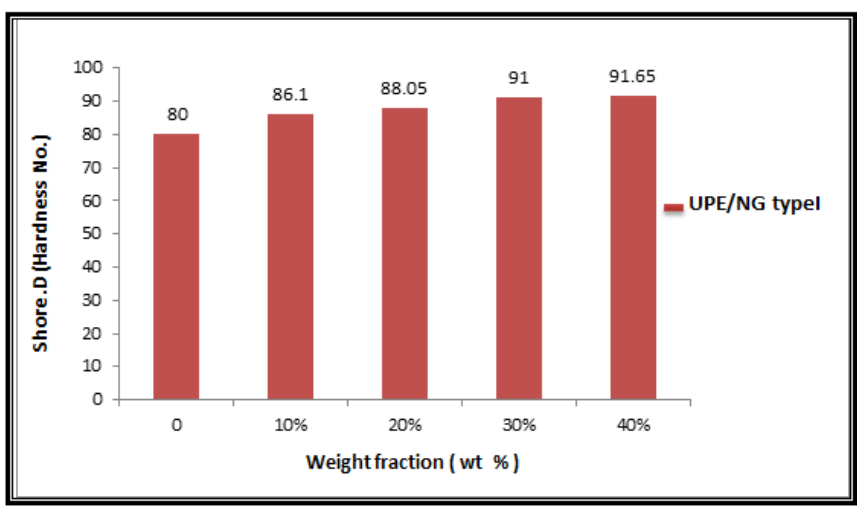

Fig. (9): shore D (Hardness No.) variation with NanoGravegl (type I) content in UPE resin

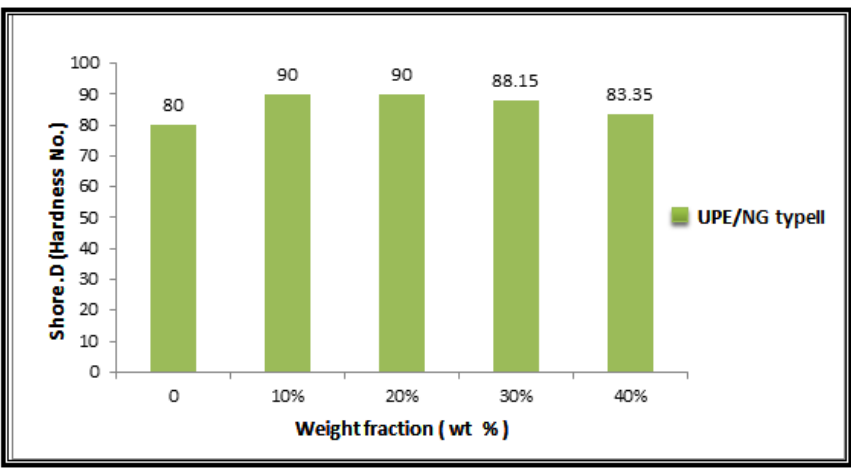

Fig. (10): shore D (Hardness No.) variation with NanoGravegl (typeII) content in UPE resin 


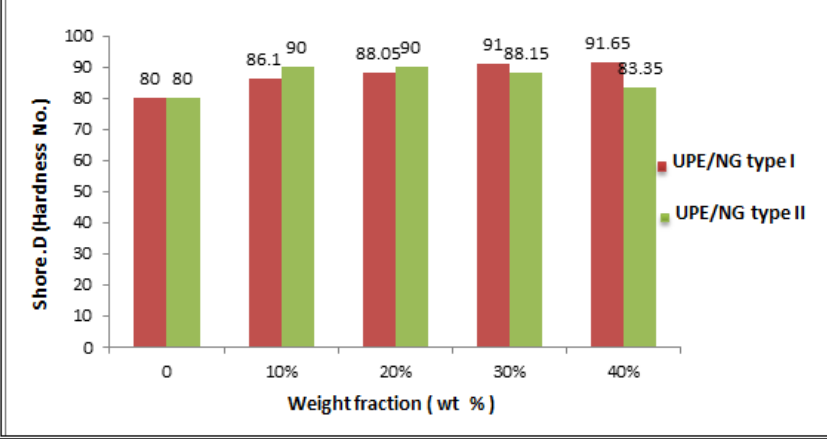

Fig. (11): shore D (Hardness No.) variation with NanoGravegl (types I and II) content in UPE resin.

\section{Conclusion}

This experimental investigation of mechanical behaviour of gravels nanoparticles as a fillers filled polyester nanocomposites leads to the following conclusions:

- The polyester resin is a good adhesive material which can use as a matrix with Gravel nanoparticles.

- The above experimental results indicate that this gravel nanoparticles may be a good filler material for polymer nanocomposite materials.

- We can produce a composite hard, strong by use small particle size of Gravel as fillers.

\section{References}

[1] Miroslav Muller, "Polymeric Composites Based on $\mathrm{AL}_{2} \mathrm{O}_{3}$ Reinforcing Particles"

Engineering for Rual Development,Jelgava, 2011.

[2] Saad M. Elia," Study the effect of Adding sea nodules powers on Flexural Strength and Hardness of Unsaturated polyester Resin", Eng.\&Tech. Journal, vol.29,No.13,2011.

[3]Gang Sui,Soumen Jana , Amin Salehi-Khojin, SaujayNeema, Wei-Hong Zhong, Huichen and OunHuo," Preparation and properties of Natural Sand Particles Reinforced Epoxy Composites", Macromolecular Materials and Engineering Journals ,2007,(467-473).

[4]Wikipedia, the free encyclopedia, "Aggregate(composite)", This page was last modified on 2 February 2013.
[5] Ahmed Jdah F. " "Investigation of Some Mechanical Properties of Sawdust and Chopped Reeds /UPE Composites". M.Sc. Thesis. Department of physics. University of Baghdad .2011.

[6]R.J.Young\&P.W.R.Beaumont ,"Failure of Brittle polymers by slow crack Growth -parts : effect of composite up on the fracture of silica particlefilled Epoxy Resin Composite", Journal of Material science, vol.12,No.4,1978.

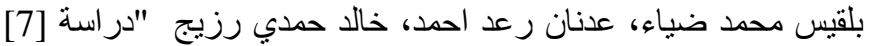
خاصيتي الصدمة و الصلادة لمو اد متر اكبةمن راتتج البولي استر

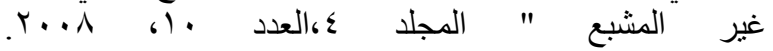

[8] Sewench N. Rafiq and NajlaaRouchdy ,"effect of filler particle size and concentration on the Mechanical and thermal properties of polymer composite",Taqani Journal, vol.23,No.1, 2010.

[9] HanaaA.S."Effect of Reinforced by Zinc oxide powder on the mechanical properties for unsaturated polyester matrix composite material" „Journal of Eng.\&Tech. ,vol.29,No. 10, 2011.

[10] WassanJ.M."Studying the physical behavioure for a particulated polymeric composite material ", M.S.C Thesis , Department of applied sciences ,Univercity of Technology,2005.

[11] Annual Book of ASTM Standareds 1984,8(1).

[12]Raghad H.M.AL - Janabi“'Studying the effect of weathering conditions on some properties of Epoxy composites". M.Sc. Thesis. Department of applied sciences. University of technology .2004.

[13]William D. Callister, Jr."Materials science and engineering. An introduction" John Wiley and sons, Inc. U.S.A. 2000. 